\title{
Operative technique: single-incision gastrostomy in pediatric patients
}

\author{
Dayang A Aziz' \\ Mahmud M Nor ${ }^{2}$ \\ 'Paediatric Surgery Unit, Department \\ of Surgery, UKM Medical Centre, \\ Bandar Tun Razak, Jalan Yaacob Latif, \\ Cheras, Kuala Lumpur, Malaysia; \\ ${ }^{2}$ Department of Surgery, Universiti \\ Sains Islam Malaysia, Kuala Lumpur, \\ Malaysia
}

This article was published in the following Dove Press journal:

Open Access Surgery

26 July 2012

Number of times this article has been viewed
Introduction: Use of minimally invasive techniques for gastrostomy insertion in children is well documented. Laparoscopic placement is fast becoming the method of choice. However, it is important to note that there are still many centers in developing and under-developed countries in which laparoscopic or endoscopic facilities are not readily available.

Methods: Here, we describe a less than $2 \mathrm{~cm}$, single-incision open gastrostomy technique successfully performed on seven infants and one child who were all malnourished. A nasogastric tube was inserted to assist the technique.

Results: All patients had a wound measuring less than $2 \mathrm{~cm}$. Mean operating time was 30 minutes. Gastrostomy tube feeding was established after 6 hours post-surgery. No complications occurred in any of the patients.

Conclusions: This technique is an excellent minimally invasive approach. It is simple, safe, and feasible.

Keywords: minimally invasive, laparoscopic placement, children, single incision

\section{Introduction}

Gastrostomy insertion in pediatric patients has evolved over the years. There are many options available, including percutaneous endoscopic, percutaneous imageguided, laparoscopic, or even open surgery. The main concerns are avoiding major complications, such as burst abdomen after open surgery in malnourished patients or gastrocolic fistula following percutaneous technique, and minimizing minor complications like surgical wound infection. ${ }^{1,2}$ Nevertheless, pediatric surgeons should strive to advocate minimally invasive techniques, as the advantages are clearly proven. ${ }^{3,4}$ Modification of open techniques via small incisions has also been described but not for gastrostomy insertion. ${ }^{5,6}$ For this technique, it is important to ensure that the stomach is easily identified, the gastrostomy tube is inserted under direct vision, and its placement is confirmed immediately by a simple maneuver.

\section{Methods}

Eight patients underwent this technique, seven of whom were under 1 year old (ie, infants). The eighth patient was 14 months old at the time of surgery. All patients were severely malnourished. Therefore, lack of thickness of the abdominal wall was an advantage for this technique. All patients had oral feeding difficulties and were dependent on full nasogastric feeding. Gastro-esophageal reflux with upper pharyngeal dysmotility was documented in two patients. Six patients were operated on in a hospital without access to laparoscopic equipment; the other two patients were scheduled
Correspondence: Dayang A Aziz Paediatric Surgery Unit, Department of Surgery, UKM Medical Centre, Bandar Tun Razak, Jalan Yaacob Latif, Cheras, Kuala Lumpur, Malaysia $\mathrm{Tel}+60123059439$

Fax +60391456684

Email dayanganita@yahoo.co.uk 
for laparoscopic gastrostomy but had relative anesthetic contraindications to laparoscopic surgery (both patients had pneumonia with bullae in the lungs). All patients were operated on by the same primary surgeon.

Preoperatively, a plain abdominal X-ray was done to ensure the transverse colon was not dilated. If there was presence of dilatation, the patient was given a saline enema to decompress the bowel. Four patients required a saline enema preoperatively. No prophylactic antibiotics were used.

A silicone gastrostomy tube with an external retention ring was used in all patients.

\section{Surgical technique}

Surgery was carried out under general anesthesia with either endotracheal intubation or application of a laryngeal mask airway. Patients were placed in a supine position. A size 10F nasogastric tube was inserted in every patient. Surgical loupes were worn to assist visualization during surgery.

The site of incision was marked with an X (Figure 1). This was taken as the midpoint of an imaginary line drawn between the left subcostal margin and the umbilicus. The primary author has performed over 60 cases of percutaneous endoscopic gastrostomy in adults and children using this exact site with no complications.

A small incision was then made with a blade and widened using monopolar diathermy. Two stay sutures were put opposite each other on the rectus muscle. Using curved artery forceps, the peritoneal cavity was carefully entered. Between 50 and $60 \mathrm{cc}$ of air was then introduced through the nasogastric tube. This immediately brought the stomach wall into the wound. Two more stay sutures were put on the stomach, with the needles allowed to remain (Figure 2). The stomach was then opened using monopolar diathermy.

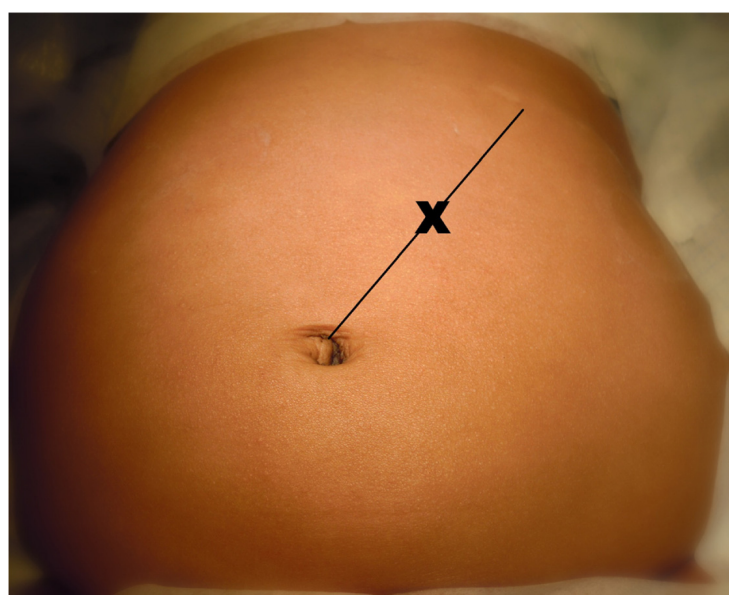

Figure I Site of incision marked with X.

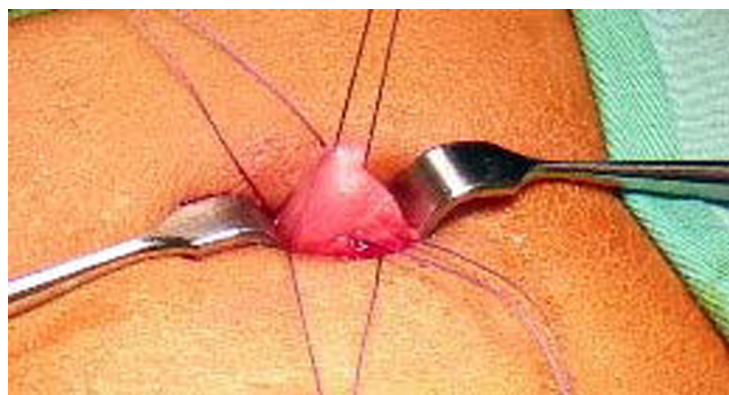

Figure 2 Stay sutures on rectus muscle and on stomach.

Next, the silicon gastrostomy tube was introduced under direct vision.

One of the gastrostomy external channels (either feeding or medicine) was then opened and submerged in a pot of water and, to check tube placement, another $50 \mathrm{cc}$ of air was introduced through the nasogastric tube - an in situ gastrostomy tube produced bubbling of water in the pot at this point (Figure 3). When available, litmus paper was also used to check if the tube was correctly placed in the stomach. A wet blue litmus paper would change to red upon contact with effluent from the tube to signify acid from the stomach.

Once placement was confirmed, the first stay suture on the stomach (with its needle still intact) was used to create a purse-string suture on the stomach to secure the tube. The gastrostomy balloon was then inflated. The second stay suture on the stomach (with the needle intact) was used to anchor the stomach wall to the rectus muscle (Figure 4). The subdermal layer was then closed with absorbable sutures (Figure 5). In the final six of our patients, cyanoacrylate was used as wound closure and wound dressing.

Finally, the external retention ring of the gastrostomy tube was securely placed on the skin overlying the wound (Figure 6).

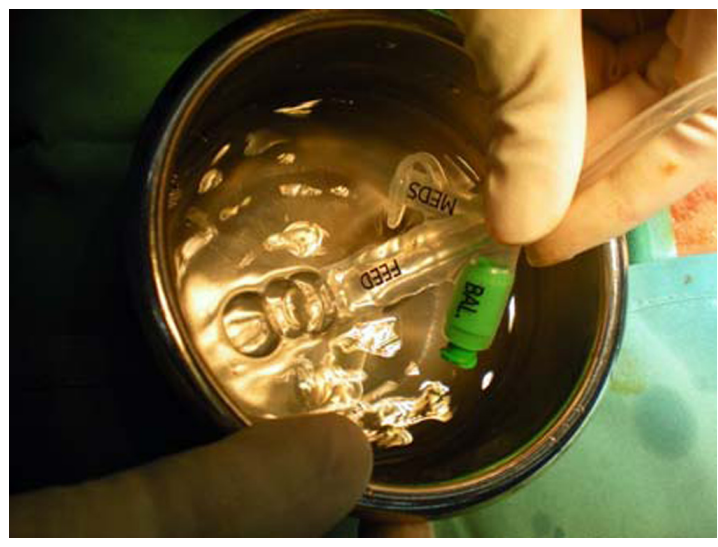

Figure 3 Water bubble is seen as air passes through gastrostomy tube following distension of stomach with $50 \mathrm{cc}$ of air through the nasogastric tube. 


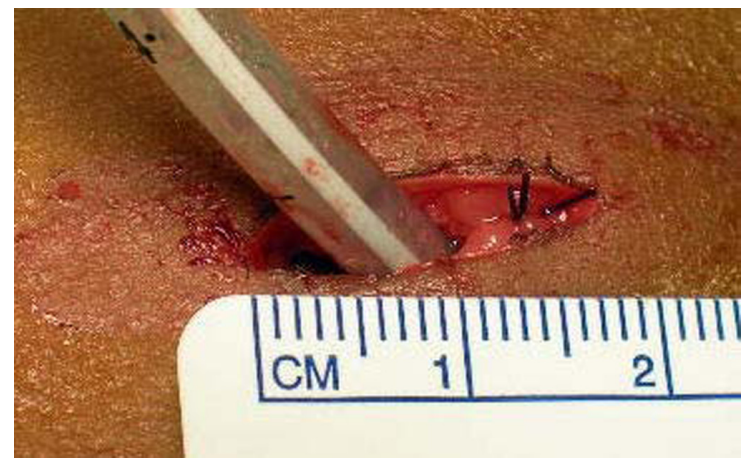

Figure 4 Gastrostomy tube anchored to anterior abdominal wall, note size of wound is less than $2 \mathrm{~cm}$.

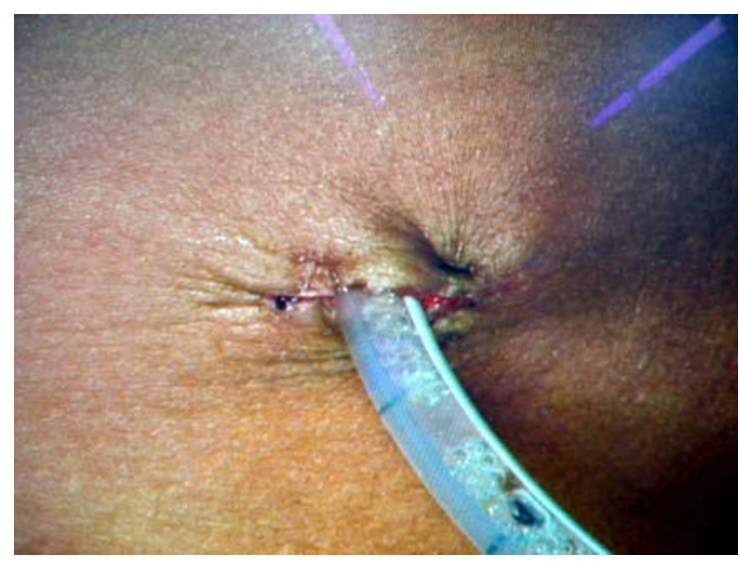

Figure 5 Gastrostomy appearance after closure of subdermal layer.

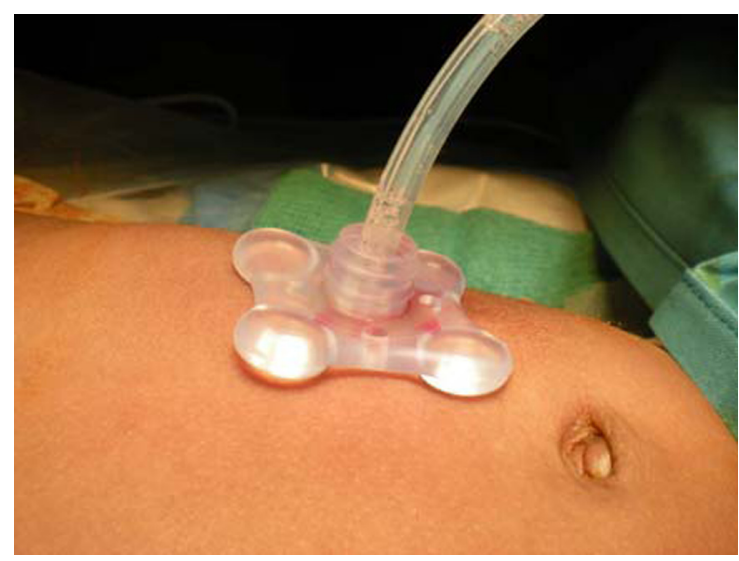

Figure 6 End result of single-incision gastrostomy insertion.
No additional sutures were created to secure the tube externally, as in percutaneous endoscopic gastrostomy.

\section{Results}

All eight patients had incisions of less than $2 \mathrm{~cm}$ long. Mean operating time was 30 minutes. Gastrostomy tube feeding was established after 6 hours post-surgery. No wound infection or dehiscence was seen up to 1 week post-surgery. None of the patients required revision of the tube. Six patients had the gastrostomy tube changed to a low-profile tube after 6 months post-surgery. Surgical follow-up was up to 1 year. All patients continued their medical follow-up with their respective pediatricians.

\section{Conclusion}

Open single-incision gastrostomy is a very simple technique. However, the technique has some limitations. Patients with esophageal atresia or stricture, in whom insertion of nasogastric tube is not permitted, will not be suitable candidates for this technique. In chubby babies or patients with a thick abdominal wall, access to the peritoneal cavity may be difficult through the small wound. Hence, even when the stomach is inflated, it may not be easy for the stomach to emerge into the wound. Nevertheless, this is a feasible and safe innovation for minimal-access gastrostomy in many pediatric patients.

\section{Disclosure}

The authors report no conflicts of interest in this work.

\section{References}

1. Lantz M, Hultin Larsson H, Arnbjörnsson E. Literature review comparing laparoscopic and percutaneous endoscopic gastrostomies in a pediatric population. Int J Pediatr. 2010; Article ID 507616.

2. Peters RT, Balduyck B, Nour S. Gastrostomy complications in infants and children: a comparative study. Pediatr Surg Int. 2010:26(7):707-709.

3. Tam P. Laparoscopic surgery in children. Arch Dis Child. 2000;82(3): 240-243.

4. Najmaldin A. Minimal access surgery in paediatrics. Arch Dis Child. 1995;72(2):107-109.

5. Emil S. Pyloromyotomy through an infra-umbilical incision: open technique and superb cosmesis. Eur J Pediatr Surg. 2009;19(2):72-75.

6. Murphy FJ, Mohee A, Khalil B, Lall A, Morabito A, Bianchi A. Versatility of the circumumbilical incision in neonatal surgery. Pediatr Surg Int. 2009;25(2):145-147.

\section{Open Access Surgery}

\section{Publish your work in this journal}

Open Access Surgery is an international, peer-reviewed, open access journal that focuses on all aspects of surgical procedures and interventions. Patient care around the peri-operative period and patient outcomes post surgery are key topics. All grades of surgery from minor cosmetic interventions to major surgical procedures are covered. Novel techniques

and the utilization of new instruments and materials, including implants and prostheses that optimize outcomes constitute major areas of interest. The manuscript management system is completely online and includes a very quick and fair peer-review system. Visit http://www.dovepress.com/ testimonials.php to read real quotes from published authors. 